\title{
Hope and advance care planning in patients with end stage renal disease: qualitative interview study
}

Sara N Davison, Christy Simpson

\begin{abstract}
Objective To understand hope in the context of advance care planning from the perspective of patients with end stage renal disease.

Design Qualitative in-depth interview study.

Setting Outpatient department of a university affiliated nephrology programme.

Participants 19 patients with end stage renal disease purposively selected from the renal insufficiency, haemodialysis, and peritoneal dialysis clinics.

Results Patients' hopes were highly individualised and were shaped by personal values. They reflected a preoccupation with their daily lives. Participants identified hope as central to the process of advance care planning in that hope helped them to determine future goals of care and provided insight into the perceived benefits of advance care planning and their willingness to engage in end of life discussions. More information earlier in the course of the illness focusing on the impact on daily life, along with empowerment of the patient and enhancing professional and personal relationships, were key factors in sustaining patients' ability to hope. This helped them to imagine possibilities for a future that were consistent with their values and hopes. The reliance on health professionals to initiate end of life discussions and the daily focus of clinical care were seen as potential barriers to hope. Conclusions Facilitated advance care planning through the provision of timely appropriate information can positively enhance rather than diminish patients' hope. Current practices concerning disclosure of prognosis are ethically and psychologically inadequate in that they do not meet the needs of patients.
\end{abstract}

\section{Introduction}

About $15-29 \%$ of deaths of patients with end stage renal disease result from a decision to discontinue dialysis. ${ }^{1}$ Comprehensive care of these patients therefore requires skill in advance care planning to lay out a set of values and processes for approaching end of life decisions and identify preferences for future goals of care. This includes attention to ethical, psychosocial, and spiritual issues related to starting, continuing, withholding, and stopping dialysis. $^{23}$ Advance care planning differs from traditional advance directives, which are legal documents that tend to outline limited treatment options and are only one optional component. The End Stage Renal Disease Workgroup on End-of-Life Care recommends that dialysis units facilitate advance care planning, yet this is not occurring. ${ }^{45}$ Patients often do not know that they have the option to withdraw from dialysis, ${ }^{6-8}$ and relatively few choose a do not resuscitate order, ${ }^{9}$ despite the extremely poor chance of survival in these patients after cardiopulmonary resuscitation. ${ }^{10}$ Patients undergoing dialysis typically do not view themselves as terminally ill and falsely assume they can be kept alive indefinitely on dialysis. Issues relating to death and dying are commonly avoided until late in the illness.

Hope can make a difference in patients' experiences with chronic illness and in how they live their lives. Patients have indicated that what healthcare providers say and do can affect their ability to hope. ${ }^{11}{ }^{12}$ Healthcare providers have an obligation to promote, maintain, and instil hope in their patients ${ }^{13}{ }^{14}$ and the ". .. moral issue of whether to tell the truth has now shifted from the disclosure of diagnosis to disclosure of prognosis." ${ }^{13}$ Can health professionals fulfil both of these responsibilities simultaneously during advance care planning? We do not know how discussions about prognosis and end of life care affect the ability of patients to hope, especially in the context of chronic illness, and whether we can sustain hope in patients with end stage renal disease yet meet their end of life needs.

\section{Methods}

We used interpretative description of interviews with patients. ${ }^{15} 16$ This technique recognises that experiences of health and illness comprise complex interactions between psychosocial and biological events and provides a conceptual description of how people experience their health and illness. This knowledge allows for the generation of new ideas and can inform clinical reasoning, innovative practices of care, and formation of policy.

\section{Recruitment and sampling}

We developed guiding questions for interviews with patients in two preliminary focus groups with eight patients in each group (four pre-dialysis and four undergoing dialysis) that highlighted issues of hope in the context of advance care planning. These issues in conjunction with a critical review of the literature guided interviews with study participants. The study consisted of 23 individual interviews with 19 purposively selected patients from a Canadian university based renal programme. Fourteen patients were recruited from the renal insufficiency clinic and were clinically expected to require dialysis within the next 12 months. The modern palliative care paradigm suggests that this is the optimal time to initiate advance care planning. We also explored emerging themes from concurrent inductive analysis and challenged them in five patients undergoing dialysis (one on

An expanded methods section can be found on bmj.com. 
haemodialysis and four on peritoneal dialysis). The nursing directors of each of the units informed patients about the study as they presented for clinics. Names of patients who were interested in participating were given to the interviewer who contacted potential participants to obtain informed consent and set up an interview time. Of the 20 patients who were approached by the nursing directors, only one refused to take part. Interviews were conducted at a time and location of the patients' choice.

\section{Data collection and analysis}

Personal open ended interviews explored participants' experiences through discussions about prognosis, end of life care, and hope and typically lasted 60-90 minutes. Four patients were interviewed twice at the patients' request to expand on issues. The interviewer was an experienced qualitative interviewer with no prior relationship to the participants. All interviews were transcribed and validated against the recorded material by the interviewer. We used inductive analysis to create an account of hope in the context of advance care planning that consisted of identifying and coding the transcribed text into themes that were synthesised to develop a cohesive conceptual description (see bmj.com for expanded methods).

\section{Results}

Patients were aged 44-88 (mean 64 years) and 11 were women. One patient was an Aboriginal Canadian and the rest were white. The cause of end stage renal disease was diabetic nephropathy in seven, hypertension in five, chronic glomerulonephritis in three, polycystic kidney disease in one, and unknown in three.

\section{The nature of hope}

Patients' hopes were personal, highly individualised, complex, and multifaceted. They were related to self, the world, setting goals, and anticipated positive outcomes. Patients' hopes were shaped by their values, reflecting what was important to them. They were personalised to correspond with their views of themselves and their spirituality and were greatly influenced by past events and relationships with significant others. For participants with negative past experiences or limited social supports, their ability to hope for a positive future was much more fragile (box $1)$.

\footnotetext{
Box 1: Nature of hope

Individualised

"Well it all goes back to my mother and she had a very long drawn out death because of heart failure and ... it's too hard on the people living, when there is no hope" (participant 16 , female)

"I have a deep and abiding faith in God and I know that life has a limitation to it and I know that we can look forward to another life, which is free of the illness and pain of this one. So that too has given me strength over the years. If life had nothing beyond this life then it would be a tragedy" (participant 2, male)

Focus on daily life

"I don't want to live on dialysis. I want to have a normal life. Hope for me now is to get back to what I've lost ... to work again, to be independent and live alone, and have the life that I had" (participant 7 , female)

"I hope to live a life that I can offer something to someone else. My commitment now is to do for other people. I don't want to be no burden on no one" (participant 8 , female)
}

Patients' hopes reflected a preoccupation with their daily lives and focused predominantly on sustaining normal lives and roles for themselves, preserving personal relationships with family and friends, minimising emotional and financial burdens, and maintaining control (box 1).

\section{Role of hope in advance care planning}

Hope was central to the process of advance care planning for these patients in that their hopes helped determine their future goals of care and provided insight into the perceived benefits of facilitated advance care planning and their willingness to engage in end of life discussions. Patients' hopes, therefore, become the cornerstone of facilitated advance care planning by providing a focus for end of life discussions (box 2).

\section{Role of health professionals and family in enhancing and} sustaining patients' hope

All participants were prepared to discuss end of life issues and looked to their healthcare providers for information; in fact, most patients wanted more information (box 3). Having this information was seen as vital in maintaining their ability to hope. This was achieved by relieving fears and by helping control the day to day aspects of life. By providing information, health professionals helped patients to imagine possibilities for a future that were consistent with their values, which in turn gave hope. As illness progressed, patients could envision life contexts where hope would be defined by finding the greatest meaning in friends and family and minimising distressing symptoms, rather than by time. Surprisingly, the potentially disturbing nature of the topic was not a major concern to these patients.

These participants needed information to be provided earlier in their illness, especially before the initiation of dialysis. They also wanted more information about their prognosis and illness and, specifically, how interventions could sustain roles and relationships-that is, preserve their concept of self (box 3). This was more important than focusing on the actual medical effectiveness of their treatment. Having staff see them in the context of their personal lives pulled them out of anonymity and enhanced the patient-physician relationship. Participants were aware of the inherent uncertainty in providing prognostic information but did not feel that this should hinder the provision of information.

Empowerment was a critical component of hope for many participants. This was primarily supported through strong trusting relationships with healthcare providers and by the provision of information, including prognostic information. By understanding their disease and the healthcare system they were now a part of and being able to predict to some extent the outcomes

\section{Box 2: Role of hope in advance care planning}

\section{Hope shapes both goals of care and advance care planning}

"Mortality is only one phase of our existence ... the end of life is no more traumatic that the beginning of life ... your only concern is leaving loved ones here for a brief time. My concern is for my wife but ... it is not a frightening factor" (participant 2, male)

"I'd like to know what is going to happen. I am very concerned about the end. I don't want it to be in my home because of my kids. Will I get a warning to go to the hospital? I don't know any of this. Like how will I know? And they don't really give me any straight answers, and that's what bothers me. I want answers. I don't want [my kids] to get up one morning to find me there, if you could understand that" (participant 17 , female) 
of their illness, they perceived greater control over their lives and how they were going to live with their disease (box 3).

Relationships with health professionals, family, and friends were vital to being able to sustain hope for many patients. These relationships were personal, existing beyond the walls of the hospital. The emotional and practical support these other individuals offered provided a broader context within which the participants could "be themselves" and integrate their experiences of illness into their daily lives. Staying connected to these relationships through working or contributing to community or family was often mentioned as a key way in which hope was sustained. The loss of one's role (how one defines oneself) and the ability to contribute to family or society threatened hope for many participants (box 3). Participants expressed greater feelings of isolation and less hope when they were not able to honestly and openly discuss their hopes and fears for the future with loved ones.

\section{Barriers to maintaining hope}

Participants expected physicians to initiate end of life discussions and looked to healthcare professionals to guide them through

Box 3: The role of health professionals and family in enhancing and sustaining hope within advance care planning

\section{More information}

"People have to have a sense of having options, even if they are not always the options they thought they would have wanted from the beginning. It's the not knowing that's the difficult part I think" (participant 11, male)

"To me having information, it's critical. Even if it's bad news I want to know what it is so I can cope with it. I want to know what's going on, what I can set myself up for" (participant 3, female)

"It all frightens me. I'm a worry-wart. I'm afraid of dialysis, I'm afraid of dying. I'm afraid, so strategies like information knock this fear down to a reasonable size and the only one I've managed to come up with so far is information" (participant 15, female)

\section{Early information}

"I would hope that healthcare providers are sufficiently trained to inform the patients at the right time what to expect and not wait until the very last minute" (participant 14, male)

\section{Information that focuses on the impact on daily life}

"The way it is nowadays nobody sees the patient, only the part they are dealing with. I enjoy going to my family doctor, who I have known for 15 years and who knows me as a person not just part of my body" (participant 4 , female)

\section{Patient empowerment}

"You've got to learn to deal with your situation. I just started reading up on it and Dr X helped me out from there ... more in education. You have to get your act together and start thinking about yourself and your family" (participant 11, male)

\section{Enhancing relationships}

"That was the worst thing with my company, when I got sick the phone calls stopped ... you've worked over 20 years for a company and all of a sudden you're like a piece of paper in the wind" (participant 18, male)

"I was very down because I feel kind of too young to feel ... to be useless in society and even to my family. I want to be with my young granddaughter that I love dearly and I don't have the energy to babysit her as often as I'd like to and play with her on the floor, and now with my access I can't even lift her up" (participant 12, female) the process of advance care planning (box 4). They did not feel they had to or should have to ask for prognostic information and were uncomfortable with exerting pressure on physicians to disclose this information. Patients were willing to take direction from their physicians about what information was important to them, trusting information would be given in a timely manner. Many indicated they would limit or suppress their questions based on cues they received from the physicians.

The day to day focus prevalent in the care of patients with end stage renal disease was also perceived as a barrier to maintaining hope. Patients had an extremely limited vision of their future; instead they focused on the concrete, day to day aspects of their illness and its management via diet and medications. Most of the predialysis patients found the limitations of comorbid conditions more important than the kidney failure itself. This day to day focus was largely created and maintained by regular interactions with healthcare professionals that concentrated almost exclusively on the moment and the success of improving or stabilising monthly blood work (box 4).

Despite the apparent lack of insight into the severity of disease, fears about dialysis and the future were common and threatened hope. Patients feared possible pain and complications; the sense of isolation and being "different" or "really sick"; and the effect dialysis would have on their relationships and valued roles in family and community. The day to day focus did not permit patients to discuss these fears with staff or provide the opportunity for effective facilitated advance care planning.

\section{Discussion}

In these patients with end stage renal failure, hope helped to determine goals of care and provided the focus for facilitated

\section{Box 4: Barriers to maintaining hope}

Reliance on health professionals to initiate end of life discussions

"I put my trust in the doctors... I trust that they know what they are doing" (participant 4 , female)

"They will tell me, they will let me know when it is time" (participant 14, female)

"I wait for them [health professionals] to tell [me] what they think ... what they think would be important for me to know" (participant 18, male)

\section{Day to day focus of clinical care}

"They put me on iron supplements for slight anaemia and the rest of the story is regular visits to the clinic, and care with diet and, of course, some medications. Basically it's a monthly reading of the test results and she makes any adjustments that are necessary, and that's basically it, I guess" (participant 3, male)

"The dialysis ... is sort of under control. It's not life threatening

... I don't think I'm going to die from kidney disease" (participant 4 , female)

"I know it's life supporting but I don't really see it that way. I don't think of it that way. You know, I think end of life is ... well basically a heart attack you know or a stroke, something like that" (participant 9, male)

"I'm in bed at night and I just worry and I get up in the morning and I just worry. Even though I'm laughing, it's only on the outside. Healthcare providers are reluctant to talk about EOL issues. I think they are afraid of how you are going to react. I don't think they know what to say. No, I want to talk about it, but nobody will talk to me. At least that's how I feel! Unless they think I'm not taking it in as much as I should because I'm laughing all the time. But, inside I am hurting like mad, but I can't get that out" (participant 19, female) 
advance care planning. The patients perceived the process of advance care planning as a means of enhancing hope by providing information early in the illness that focuses on the impact on daily life, empowering patients and enhancing relationships with staff and loved ones. Conversely, the reliance on health professionals to initiate end of life discussions and the daily focus of clinical care were perceived to be potential barriers to hope.

Many health professionals believe that end of life discussions may destroy hope for patients with end stage renal disease. ${ }^{17-19}$ These beliefs may originate from the perception that denial-like coping mechanisms are commonly used to adapt to life on dialysis as most patients seem unaware of possible imminent death. ${ }^{60}$ Hope is a complex multidimensional construct that provides comfort during life's challenges. Hope limits the range of information that patients take into account, the inferences drawn from the information, and the set of options among which they will choose. ${ }^{21}{ }^{22}$ Gaps exist in our knowledge with regard to how hope is derived and how it influences clinical outcomes.

Physicians admit to a lack of accurate survival statistics and often feel that patients either do not understand or misinterpret statistics. ${ }^{23}$ In our study, however, hope had relatively little to do with the statistical effectiveness of treatment. Participants looked to physicians for assistance in making the necessary connections between their lives and the vast array of information available to them. Helping patients see future possibilities consistent with their values is what maintains hope. People also change as they learn more about their illness and "who they are" or can be in the context of that illness. As illness progresses, health professionals, through advance care planning, play a critical part in reshaping what patients imagine for their future and what they hope for. These findings are consistent with and supported by the literature on hope in other groups of patients, ${ }^{24}{ }^{25}$ and open discussion of prognosis has been associated with less emotional distress in terminally ill patients during the dying process. ${ }^{26}$

Given the preoccupation with routine monitoring combined with avoidance of prognosis and end of life discussions, it is not surprising that many patients maintain unrealistic expectations for their goals of care and survival. And yet "the creation of an experience of hope through an emphasis on temporality and on experience 'for the moment' is often fraught with great anxiety for patients. ..."27 This tension was clearly evident in our participants; unaddressed fears about the future and a lack of preparation for what lay ahead were constant threats to hope. It's difficult to have hope for the future if you cannot see beyond the moment. With the provision of prognostic information, new threats will be perceived, but rather than annihilate hope, it provides an opportunity to reshape hopes, making them more consistent with the future.

Most of these patients accepted physicians as the gatekeepers of information, over-riding their preferences for more information in favour of the conversation pattern established by their physician. This leads to a unique tension in the patient-physician relationship: patients may not participate in facilitated advance care planning because they feel it is not relevant rather than because they inherently reject the idea. Physicians need to find ways in which to initiate these discussions and indicate to patients that these issues are relevant. The other obvious problem is the difference in perception as to the appropriate time to initiate advance care planning. For patients, this occurs much earlier than perceived by physicians. Although physicians worry that disclosure of poor prognosis could interfere with establishing trust, these patients identified the advance care planning process as an important element in a trusting patient- physician relationship and felt this relationship was threatened when their concerns were not addressed.

\section{Validity of findings}

Qualitative research makes no claim to generalisability. This study was done in a primarily white population and obviously ethnicity and religion will shape patients' hopes and attitudes about advance care planning and end of life care. There will always be variability in patients' desire for information and involvement in medical decision making, and health professionals need to be guided by patients' preferences. By virtue of its reliance on interpretation, interpretative description cannot yield "facts" but rather "constructed truths." While it is naive to assume all biases have been eliminated, the validity of our findings is supported by repeated interviewing in which developing concepts were subjected to challenges and by checking the data for anomalies. Validity is also supported by the integration of and reference to clinical observations and the available relevant literature.

These data deepen our understanding of hope in the context of facilitated advance care planning and show that, through the provision of timely appropriate information, it can positively enhance rather than diminish patients' hope. We have also provided some evidence that our current disclosure practices are ethically and psychologically inadequate in that they do not meet the needs of our patients. Although this study was done in the context of end stage renal disease, these data are probably relevant to all clinicians who treat people with advanced disease.

Contributors: SD was responsible for study conception, design, conduct, analysis, and manuscript preparation, controlled the decision to publish, and is guarantor. CS was involved at all stages of the analysis and contributed to the writing of the manuscript.

Funding: Amgen Canada.

Competing interests: None declared.

Ethical approval: University of Alberta research ethics board.

1 US Renal Data System, National Institutes of Health, and National Institute of Diabetes and Digestive and Kidney Diseases. US renal data system; USRDS 2004. 2004 annual data report: atlas of end-stage renal disease in the United States. Bethesda, MD: US Renal Data System, National Institutes of Health, and National Institute of Diabetes and Digestive and Kidney Diseases, 2004.

2 Chambers EJ, Germain M, Brown E. Supportive care for the renal patient. 1st ed. New York,: Oxford University Press, 2004:1-267.

\section{What is already known on this topic}

Advance care planning allows patients to prepare for death, strengthen relationships with loved ones, achieve a sense of control, and relieve burdens placed on others

Sometimes such planning is not done because health providers are reluctant to engage in end of life discussions for fear of destroying patients' hope

Hope can affect patients' experiences with chronic illness, can help with the coping process, and enhance quality of life

\section{What this study adds}

Participants need more and earlier information with a focus on how treatment options would affect their daily lives

Reliance on health professionals to initiate advance care planning and the daily focus on clinical care without attention to future goals of care are barriers to maintaining hope 
3 Davison S. Quality end-of-life care in hemodialysis units. Semin Dial 2002;15:1-4.

4 Holley JL, Nespor S, Rault R. The effects of providing chronic hemodialysis patients with material on advance directives. Am J Kidney Dis 1993;22:413-8.

5 Holley JL, Hines SC, Glover JJ, Babrow AS, Badzek LA, Moss AH. Failure of advance care planning to elicit patients' preferences for withdrawal from dialysis. Am J Kidney Dis 1999;33:688-93.

6 Cohen LM, Germain M, Woods A, Gilman ED, McCue JD. Patient attitudes and psychological considerations in dialysis discontinuation. Psychosomatics 1993;34:395401.

7 Hines SC, Glover JJ, Holley JL, Babrow AS, Badzek LA, Moss AH. Dialysis patients' preferences for family-based advance care planning. Ann Intern Med 1999;130:825-8.

Hines SC, Glover IJ, Babrow AS, Holley JL, Badzek LA, Moss AH. Improving advance care planning by accommodating family preferences. J Palliat Med 2001;4:481-9.

9 Moss AH, Hozayen O, King K, Holley JL, Schmidt RJ. Attitudes of patients toward cardiopulmonary resuscitation in the dialysis unit. Am J Kidney Dis 2001;38:847-52.

10 Moss AH, Holley JL, Upton MB. Outcomes of cardiopulmonary resuscitation in dialysis patients. J Am Soc Nephrol 1992;3:1238-43.

11 Sardell AN, Trierweiler SJ. Disclosing the cancer diagnosis: procedures that influence patient hopefulness. Cancer 1993;72:3355-65.

12 Wong-Wylie G, Jevne RF. Patient hope: exploring the interactions between physicians and HIV seropositive individuals. Oual Health Res 1997:7:56.

13 Kodish E, Post SG. Oncology and hope.J Clin Oncol 1995;13:1817-22.

14 Elliott TR, Witty TE, Herrick S, Hoffman JT. Negotiating reality after physical loss: hope depression, and disability. J Pers Soc Psychol 1991;61:608-13.

15 Thorne S, Kirkham SR, MacDonald-Emes J. Interpretive description: a noncategorical qualitative alternative for developing nursing knowledge. Res Nurs Health 1997;20:169qualitative alternative for developing nursing knowledge. Res Nurs Health 1997;20:169-

16 Thorne S, Reimer Kirkham S, O'Flynn-Magee K. The analytic challenge in interpretive description. Int J Qual Methods 2004;3:1-21.

17 Johnston SC, Pfeifer MP, McNutt R, for the End-of-Life Study Group. The discussion about advance directives. Patient and physician opinions regarding when and how it should be conducted. Arch Intern Med 1995;155:1025-30.
18 Morrison RS, Morrison EW, Glickman DF. Physician reluctance to discuss advance directives. Arch Intern Med 1994;154:2311-8.

19 Perry E, Swartz R, Smith-Wheelock L, Westbrook J, Buck C. Why is it difficult for staff to discuss advance directives with chronic dialysis patients? J Am Soc Nephrol 1996; 7:2160-70.

20 Cohen LM, McCue JD, Germain M, Woods A. Denying the dying. Advance directives and dialysis discontinuation. Psychosomatics 1997;38:27-34.

21 de Sousa R. The rationality of emotion. Cambridge, MA: MIT Press, 1987:195.

22 Simpson C. When hope makes us vulnerable: a discussion of patient-health care provider interactions in the context of hope. Bioethics 2004;18:428-47.

23 Mivaji NT. The power of compassion: truth-telling among American doctors in the care of dying patients. Soc Sci Med 1993;36:264.

24 Carson V, Soeken K, Shanty J, Terry L. Hope and spiritual well-being: essentials for living with AIDS. Perspect Psychiatr Care 1990;26:28-34.

25 Forbes M. Hope in older adults with chronic illness. Appl Nurs Res 1999;22:74-87.

26 Christakis NA. Death foretold: prophecy and prognosis in medical care. Chicago: University of Chicago Press, 1999 .

27 Del Vecchio Good M, Munakata T, Kobayashi Y, Mattingly C, Good BJ. Oncology and narrative time. Soc Sci Med 1994;38:855-62.

(Accepted 23 August 2006)

doi $10.1136 /$ bmj. 38965.626250 .55

Division of Nephrology and Immunology, University of Alberta, Edmonton, Alberta, Canada

Sara N Davison assistant professor, medicine

Department of Bioethics, Dalhousie University, Halifax, Nova Scotia, Canada

Christy Simpson assistant professor

Correspondence to: S N Davison sara.davison@ualberta.ca 